\title{
Total Hip Arthroplasty in Patients with Active Tuberculosis of the Hip with Advanced Arthritis
}

\author{
Devdatta Suhas Neogi MS (Ortho), DNB, MCh.Orth, MRCSEd, \\ Chandra Shekhar Yadav MS (Ortho), \\ Ashok Kumar MS (Ortho), Shah Alam Khan MS (Ortho), DNB, MCh.Orth (Liv), FRCS (Glasg), \\ Shishir Rastogi MS (Ortho), DNB
}

Received: 2 January 2009/Accepted: 15 June 2009/Published online: 30 June 2009

(C) The Association of Bone and Joint Surgeons (B) 2009

\begin{abstract}
Osteoarticular tuberculosis (TB) in the hip and other joints is increasing and patients in developing countries commonly present with advanced joint destruction. We asked whether TB is reactivated after THA in these patients. We retrospectively reviewed 12 patients with an average age of 45 years who had advanced stages of hip destruction secondary to mycobacterium TB and who were treated with primary THA and prescribed perioperative antituberculous medication for 12 to 18 months postoperatively. Diagnosis in all these patients was confirmed by histopathology and culture. The minimum followup was 25 months (average, 41 months; range, 25-58 months). We observed no reactivation of TB in 11 patients who had Harris hip scores ranging from 86 to 97 . One patient who postoperatively did not comply with the antituberculous chemotherapy had reactivation and superimposed infection through a nonhealing sinus tract; that patient underwent component removal and resection arthroplasty. When the infected tissue can be débrided and adequate antituberculous therapy is instituted the outcome of joint arthroplasty may not be adversely affected. THA in the tuberculous hip has a low risk of reactivation and produces good functional results.
\end{abstract}

Each author certifies that he or she has no commercial associations (eg, consultancies, stock ownership, equity interest, patent/licensing arrangements, etc) that might pose a conflict of interest in connection with the submitted article.

Each author certifies that his or her institution has approved the human protocol for this investigation, that all investigations were conducted in conformity with ethical principles of research, and that informed consent for participation in the study was obtained.

D. S. Neogi, C. S. Yadav (凹), Ashok Kumar,

S. A. Khan, S. Rastogi

Department of Orthopaedics, All India Institute of Medical

Sciences, Ansari Nagar, New Delhi 110029, India

e-mail: drdevdatt@yahoo.co.in
Level of Evidence: Level IV, therapeutic case series (no, or historical control group). See the Guidelines for Authors for a complete description of levels of evidence.

\section{Introduction}

The World Health Organization estimated the incidence of $\mathrm{TB}$ to be 8.8 million, smear-positive 3.9 million, and mortality approximately 1.6 million in 2005 [24]. There has been an increase in the incidence of osteoarticular TB reported in western countries [18]. The main reasons for this epidemiologic trend include an increase in immigration from regions where TB is endemic, an increase in the number of people with immune suppression, aging of the population, and development of drug-resistant strains of mycobacterium tuberculosis (MTB) [18]. Infection of the musculoskeletal system accounts for $1 \%$ to $5 \%$ of all patients with TB, whereas TB of the hip constitutes $10 \%$ to $15 \%$ of all patients with osteoarticular TB [2, 23].

Socioeconomic constraints and the fear of being a social outcast in the developing world cause these patients to delay presentation for treatment, by which time the joint no longer is able to be preserved. Arthrodesis and resection arthroplasty are offered to patients in whom hip function is unsatisfactory $[2,15,23]$. THA has been the accepted procedure in quiescent TB; however, the reported time for the hip to become quiescent has varied from 10 to 20 years [10, 12, 13, 15-17]. A history of activity of infection within 10 years, chronic discharging sinus tract, and positive culture of tissue obtained during surgery reportedly increase the risk reactivation of infection [15-17, 25].

Bacteria adhering to implanted medical devices or damaged tissues can encase themselves in a hydrated matrix of polysaccharide and protein forming a slimy layer known as a 
biofilm [22]. Antibiotic resistance of bacteria in the biofilm mode of growth contributes to the chronicity of infection [22]. Metal implants have been used in patients with spinal $\mathrm{TB}$ and have been reported to have good results with no reactivation [7, 9, 21]. In addition, in vitro studies comparing the adherence and biofilm properties of MTB and staphylococcus epidermidis suggest MTB rarely adheres to a metal surface and has little or no biofilm formation, thus making it more susceptible to antibiotic therapy [9,21].

The in vitro studies of biofilm formation, the success with using implants [7, 9, 21], and the good functional results with no reactivation reported for THA in patients with active TB of the hip [15, 25] prompted us to evaluate the use of THA in patients with active advanced TB of the hip particularly in relation to reactivation, function, and laboratory findings.

\section{Materials and Methods}

We retrospectively reviewed all 12 patients with advanced active TB of the hip treated with a primary one-stage THA at our institute between January 2003 and June 2006. Advanced tubercular arthritis was defined as when patients had clinical features of pain, deformity, restriction of motion, and wasting with radiographically apparent destruction of the articular surface and bone on either side, wandering acetabulum, subluxated or dislocated hip, MR images of gross destruction and surrounding abscess (Fig. 1), and supported by hematologic investigations. Thus, we only included patients with clinically and radiographically advanced Stage III or Stage IV TB in the study $[2,23]$. We excluded patients involved in heavy activity, those with Stages I and II TB [2, 23], and those with other sites of involvement. Patients with Stages I and II TB are known to heal well and have good function after antitubercular chemotherapy (ATT) [2]. THA may not be a good procedure for people involved in heavy manual labor, therefore, these patients were excluded. We presumed involvement of another site signified more immunosuppression, and therefore, we did not offer immediate THA to these patients. There were seven women and five men with an average age of 45 years (range, 26-63 years) (Table 1). Pain, deformity, restriction of motion, and limb wasting

Fig. 1A-D Preoperative radiographs show (A) femoral head destruction and (B) subluxation. (C) An MR scan shows active disease with a soft tissue abscess. (D) A radiograph obtained at the 43-month followup shows no evidence of osteolysis or disease reactivation.
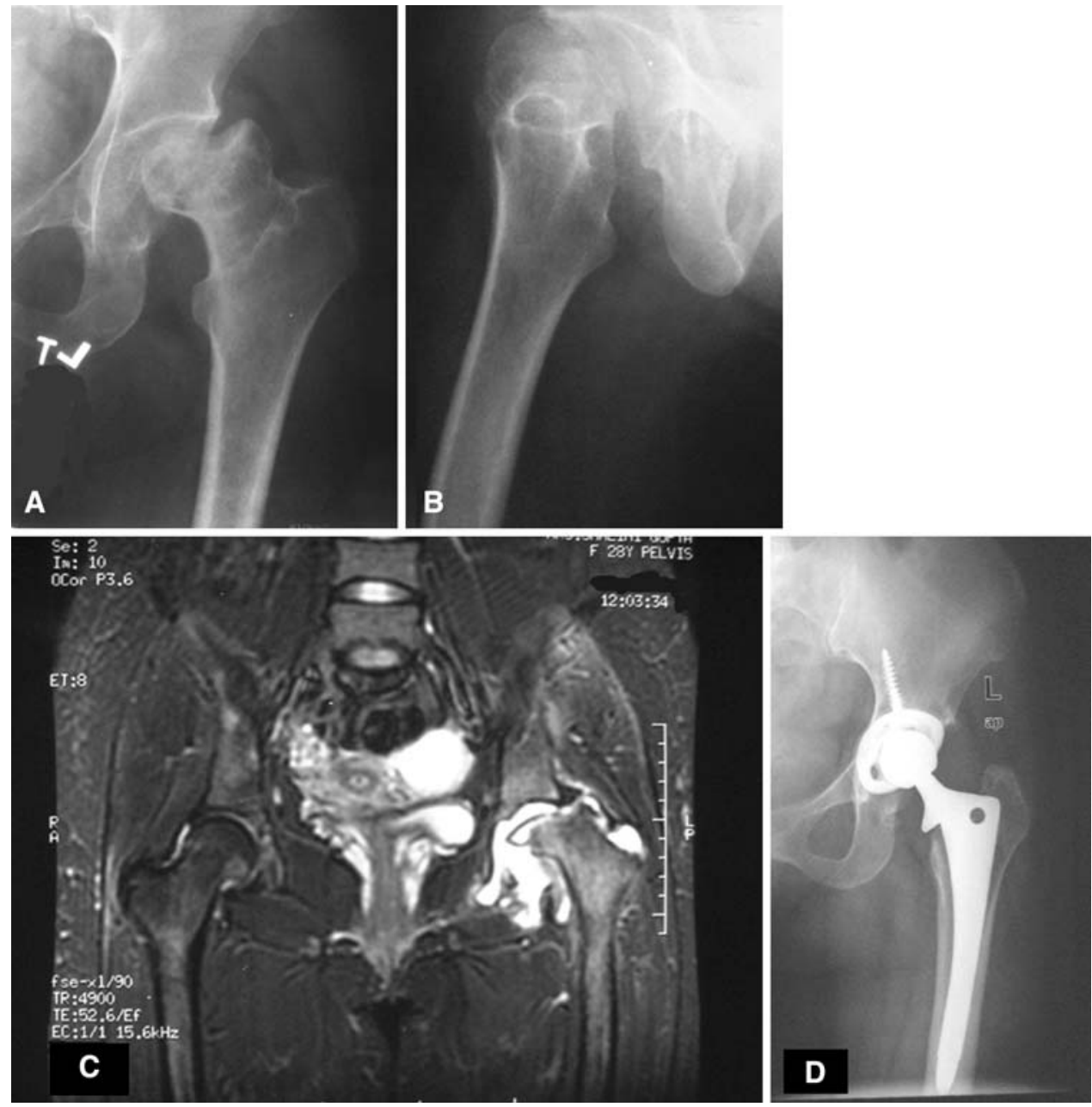
were present in all patients; a sinus was present in one. No patient had any other active focus of TB at presentation. Two patients had a history of pulmonary TB treated by ATT for 6 months and both showed a healed focus on their chest radiograph and were sputum-negative for acid-fast bacilli (AFB) and MTB. The minimum followup was

Table 1. Patient demographics

\begin{tabular}{lllll}
\hline Patient & $\begin{array}{l}\text { Age } \\
\text { (years) }\end{array}$ & Gender & Clinical features & $\begin{array}{l}\text { ATT before } \\
\text { presentation }\end{array}$ \\
\hline 1 & 50 & Female & P/D/RM/W/LW/F & No \\
2 & 62 & Female & P/D/RM/W/LW/F & 8 weeks \\
3 & 44 & Male & P/D/RM/W/LW & No \\
4 & 32 & Female & P/D/RM/W/LW/F & No \\
5 & 45 & Female & P/D/RM/W/LW/F & No \\
6 & 26 & Male & P/D/RM/W/LW/F & 4 weeks \\
7 & 40 & Male & P/D/RM/W/LW & No \\
8 & 63 & Male & P/D/RM/W/LW/F & No \\
9 & 43 & Female & P/D/RM/W/LW/F & No \\
10 & 39 & Male & P/D/RM/W/LW/F & No \\
11 & 52 & Female & P/D/RM/W/LW/S & No \\
12 & 46 & Female & P/D/RM/W/LW/F & No \\
\hline
\end{tabular}

$\mathrm{P}=$ pain $; \quad \mathrm{D}=$ deformity $; \quad \mathrm{RM}=$ restricted movements $\quad \mathrm{W}=$ weight loss; $\mathrm{LW}=$ limb wasting; $\mathrm{F}=$ low grade fever; $\mathrm{S}=$ sinus.
25 months (average, 41 months; range, 25-58 months). No patients were lost to followup.

All patients were counseled regarding the procedure and preoperative and postoperative therapy, and informed consent was obtained. After obtaining ethical board clearance, we reviewed patients' records to identify the presentation, treatment details, operative details, and implants used (Table 2). Preoperatively, a thorough history of diagnosis for past tuberculous infection or for any history of contact with a patient with tuberculous infection was obtained routinely. We obtained chest, spine and radiographs of other bones in all patients when symptomatic to rule out any other osteoarticular active foci of infection because we thought this may increase operative risks. Sputum for detection of AFB and culture was sent for microbiologic examination in all patients. We performed a hemogram, enzyme-linked immunosorbent assay for HIV, hepatitis B antigen, and routine biochemical investigations (ie, serum blood chemistry for sugar, urea, and creatinine) to rule out lowered immune status and for preoperative fitness.

Preoperatively, ATT was started with four drugs: $5 \mathrm{mg} /$ $\mathrm{kg}$ isoniazid, $10 \mathrm{mg} / \mathrm{kg}$ rifampicin, $15 \mathrm{mg} / \mathrm{kg}$ ethambutol, and $25 \mathrm{mg} / \mathrm{kg}$ pyrizinamide daily for at least 4 weeks accompanied by domiciliary traction. THA was performed in all patients. Perioperatively, cephalosporin cover was given for 3 days. The average duration of preoperative ATT was 5 weeks. Patient 11 had a sinus that healed with

Table 2. Management

\begin{tabular}{|c|c|c|c|c|c|c|c|c|c|c|c|}
\hline \multirow[t]{2}{*}{$\begin{array}{l}\text { Patient } \\
\text { number }\end{array}$} & \multicolumn{3}{|c|}{$\begin{array}{l}\text { Preoperative } \\
\text { investigations }\end{array}$} & \multirow{2}{*}{$\begin{array}{l}\text { Preoperative } \\
\text { ATT } \\
\text { (weeks) }\end{array}$} & \multirow[t]{2}{*}{ Procedure } & \multicolumn{3}{|c|}{$\begin{array}{l}\text { Postoperative } \\
\text { investigations }\end{array}$} & \multirow[t]{2}{*}{$\begin{array}{l}\text { Therapy } \\
\text { compliance }\end{array}$} & \multirow{2}{*}{$\begin{array}{l}\text { Postoperative } \\
\text { ATT } \\
\text { (months) }\end{array}$} & \multirow[t]{2}{*}{$\begin{array}{l}\text { Additional } \\
\text { procedures }\end{array}$} \\
\hline & $\begin{array}{l}\text { Chest } \\
\text { xray }\end{array}$ & $\begin{array}{l}\text { ESR } \\
(\mathrm{mm})\end{array}$ & $\begin{array}{l}\text { Xray/ } \\
\text { MRI }\end{array}$ & & & $\begin{array}{l}\text { Biopsy } \\
\text { culture }\end{array}$ & $\begin{array}{l}\text { Histo- } \\
\text { pathology }\end{array}$ & PCR & & & \\
\hline 1 & $\mathrm{~N}$ & 55 & $\mathrm{De}, \mathrm{A}$ & 5 & UC-THA & + & Ty & $\mathrm{Nd}$ & Yes & 12 & No \\
\hline 2 & $\mathrm{~N}$ & 60 & $\mathrm{De}, \mathrm{A}$ & 6 & H-THA & - & Ty & + & Yes & 18 & No \\
\hline 3 & $\mathrm{HF}$ & 45 & $\mathrm{De}, \mathrm{Dl}, \mathrm{A}$ & 4 & UC-THA & - & ATy & + & Yes & 12 & No \\
\hline 4 & $\mathrm{~N}$ & 35 & $\mathrm{Sb}, \mathrm{De}, \mathrm{A}$ & 4 & UC-THA & - & Ty & $\mathrm{Nd}$ & Yes & 12 & No \\
\hline 5 & $\mathrm{~N}$ & 80 & De, A & 4 & UC-THA & + & Ty & $\mathrm{Nd}$ & Yes & 12 & No \\
\hline 6 & $\mathrm{~N}$ & 60 & $\mathrm{De}, \mathrm{A}$ & 5 & UC-THA & - & ATy & + & Yes & 12 & No \\
\hline 7 & $\mathrm{~N}$ & 64 & $\mathrm{Sb}, \mathrm{A}$ & 4 & UC-THA & + & Ty & $\mathrm{Nd}$ & Yes & 18 & No \\
\hline 8 & $\mathrm{HF}$ & 52 & De, A & 6 & UC-THA & + & Ty & + & Yes & 18 & No \\
\hline 9 & $\mathrm{~N}$ & 43 & De, A & 5 & UC-THA & - & Ty & + & Yes & 12 & No \\
\hline 10 & $\mathrm{~N}$ & 50 & Sb,De, A & 4 & UC-THA & - & Ty & + & Yes & 12 & No \\
\hline 11 & $\mathrm{~N}$ & 45 & $\mathrm{De}, \mathrm{A}$ & 8 & H-ТHA & - & Ty & $\mathrm{Nd}$ & $\begin{array}{l}\mathrm{No} / \\
\quad \text { Persistence } \\
\quad+\mathrm{SA}\end{array}$ & 18 & $\begin{array}{l}2 \text { Debridements, } \\
\text { later implant } \\
\text { removal }\end{array}$ \\
\hline 12 & $\mathrm{~N}$ & 48 & $\mathrm{De}, \mathrm{A}$ & 5 & UC-THA & + & Ty & + & Yes & 12 & No \\
\hline
\end{tabular}

$\mathrm{N}=$ normal; $\mathrm{HF}=$ healed focus; ESR = erythrocyte sedimentation rate at end of $1^{\text {st }}$ hour in $\mathrm{mm}$; De = destruction of hip on both sides; $\mathrm{Sb}=$ subluxation; $\mathrm{Dl}=$ dislocation; $\mathrm{A}=$ abscess; UC-THA = uncemented THA; H-THA = hybrid THA; Ty = typical; ATy = atypical; $\mathrm{PCR}=$ polymerase chain reaction; $\mathrm{N}=$ not done; $\mathrm{SA}=$ superadded Staphylococcus aureus infection. 
ATT by 6 weeks and was prescribed an additional 2 weeks therapy until the index procedure.

All THAs were performed using a posterior approach. After splitting the gluteus maximus, we found delineation of the short external rotators difficult owing to surrounding fibrosis. Given osteoporotic bones, we took extra care when dislocating the hip. During reaming we ensured the reamer was in the center to minimize the risk of cortical perforation. We curetted cavities in the acetabulum when present. Owing to the presence of inflammation, soft tissue bleeding tended to be greater; we therefore ensured adequate hemostasis and availability of blood replacement when needed. Abscesses detected on preoperative scans were drained. Necrotic tissue, when present, needed adequate débridement. All patients had cementless fixation on the acetabular side; on the femoral side 10 patients had cementless fixation and two patients had cemented fixation. The AML plus femoral stem (DePuy, Warsaw, IN, USA), Durolac shell (DePuy), and liner with a 28-mm metal head (DePuy) were used in four patients; the Corail femoral stem (DePuy, Leeds, UK), Pinnacle acetabulum cup and liner (DePuy [USA]), and 28-mm head (DePuy [USA]) were used in three patients; the CPT femoral stem
(Zimmer, Warsaw, IN, USA), Trilogy acetabular system (Zimmer), and 28-mm head (Zimmer) were used in two patients; and the Accolade femoral stem (Stryker Orthopaedics, Mahwah, NJ, USA), Trident shell and polyethylene liner (Stryker Orthopaedics), and 36-mm femoral head (Stryker Orthopaedics) were used in two patients. On the acetabular side, we used one to three cancellous screws in all patients. Morselized allograft bone grafting was used on the acetabular side in one patient (Fig. 2). Medium-sized cavities $(1-2 \mathrm{~cm})$ in two patients were filled with iliac crest autograft and small cavities (less than $1 \mathrm{~cm}$ ) were left unfilled. During reduction of the prosthesis, difficulty owing to preexisting contractures was encountered, and therefore psoas release was performed in three patients and adductor release in nine patients. In all patients, the material obtained was sent for staining, culture, and histopathologic examination. We performed polymerase chain reaction for the presence of the mpt64 [2] gene of MTB in seven patients.

All patients wore graduated compression stockings and used foot pumps for postoperative thromboprophylaxis. Traction was used for 1 to 2 weeks. In-bed mobilization was started on the second day. Toe-touch weightbearing
Fig. 2A-E A preoperative radiograph shows (A) femoral head destruction and a large acetabular cavity (arrow) with periarticular osteopenia. (B) Anteroposterior and $(\mathbf{C})$ lateral radiographs show the hips after THA and reconstruction of an acetabular defect with morselized allograft bone grafting (arrow). Followup (D) anteroposterior and (E) lateral radiographs obtained at 45 months show good incorporation of the allograft (arrow), and no evidence of osteolysis or reactivation.
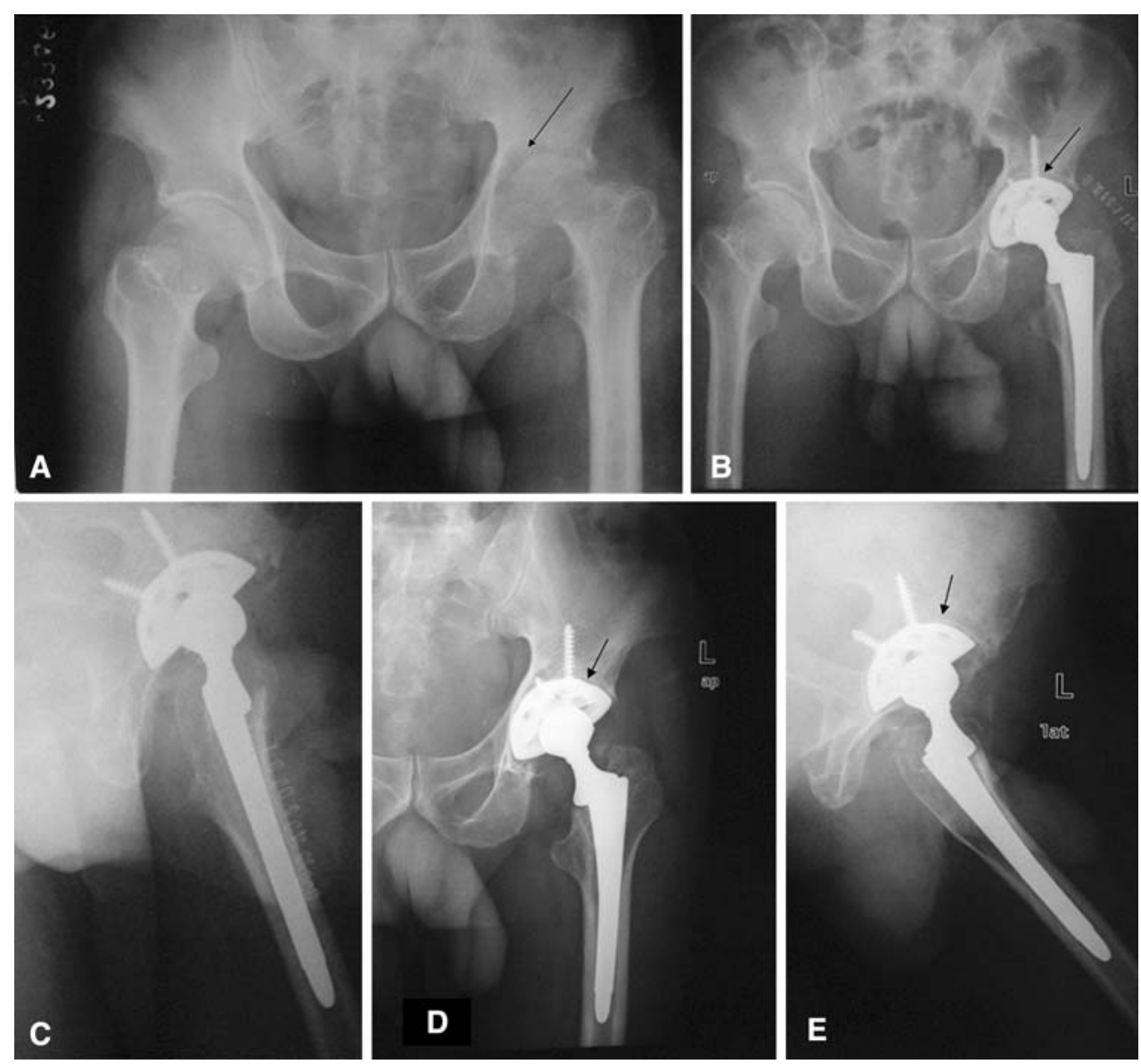
and crutch walking were allowed from the tenth day and continued for up to 8 to 12 weeks; full weightbearing was allowed only after that.

All patients were prescribed ATT with isoniazid, rifampicin, ethambutol, and pyrizinamide postoperatively for the first 4 months; isoniazid, rifampicin, and pyrizinamide were prescribed for an additional 4 months; and isoniazid and rifampicin were prescribed for another 4 to 10 months. Thus patients whose ESR and CRP were normal by the fifth month were given postoperative ATT for a total of 1 year, whereas for patients whose values remained above normal, the decision was made to continue ATT up to 18 months.

Patients were seen for followup every 4 weeks after discharge for the first 6 months and evaluated with the Harris hip score (HHS) [11], erythrocyte sedimentation rate (ESR), C-reactive protein (CRP), and liver function tests. We obtained anteroposterior and lateral radiographs every 8 weeks. From 6 months to 1 year, patients were called once in 8 weeks and all the previous parameters were tested, whereas during the second year, patients were followed up every 3 months for the first 6 months and thereafter were called once in 6 months, with all the previous parameters. The radiographic techniques were standardized across all patients and for each radiographic view. Anteroposterior and lateral radiographs were assessed by the senior authors (CSY, SAK) by comparing them with previous radiographs for change in overall bone density, any new and progressive radiolucent lines or cavities, and implant subsidence and migration. The femoral component and associated interfaces were divided into seven zones, as described by Gruen et al. [8], whereas the acetabular component and surrounding bone were divided into three zones, as described by DeLee and Charnley [4]. The Engh and Bobyn classification system [5] for implant fixation based on radiographic inspection was used to assess the cementless femoral components.

\section{Results}

One patient had reactivation of the infections. She was noncompliant with ATT and was lost to followup 2 months postoperatively. After 4 months, she returned with infection and a discharging sinus. She underwent two débridements. Cultures showed a superinfection with Staphylococcus aureus, and the patient subsequently underwent implant removal and resection arthroplasty. MTB culture sensitivity was obtained from surgical specimens that showed sensitivity to all first-line drugs, which were continued for 18 months under supervision. No reactivation was seen in other patients at last followup. There was no postoperative dislocation or any neurologic or vascular complications in the remaining patients.

The preoperative pain score (component of HHS) improved from a mean of $5(\mathrm{SD}= \pm 5)$ to a mean of 30 $(\mathrm{SD}=0)$ by 1 month postoperative. The HHS improved from a mean of $38(\mathrm{SD}= \pm 6)$ to a mean of $88(\mathrm{SD}=$ \pm 11 ) by the last followup (Table 3 ). Range of movement in the flexion-extension plane improved from an average of $35^{\circ}$ (range, $15^{\circ}-50^{\circ}$ ) to an average of $108^{\circ}$ (range, $70^{\circ}$ $120^{\circ}$ ). Eleven patients did not use a walking aid at followup.

Culture specimens were positive for five patients; histopathologic analysis was positive for all patients, with typical epithelioid granuloma with or without caseation seen in 10 patients and poorly formed granuloma in two

Table 3. Followup

\begin{tabular}{|c|c|c|c|c|c|}
\hline \multirow{2}{*}{$\begin{array}{l}\text { Patient } \\
\text { number }\end{array}$} & \multirow{2}{*}{$\begin{array}{l}\text { Followup } \\
\text { (months) }\end{array}$} & \multicolumn{2}{|c|}{ Harris hip score } & \multirow{2}{*}{$\begin{array}{l}\text { Total range of movement } \\
\text { (flexion - extension) }\end{array}$} & \multirow[t]{2}{*}{ Reactivation } \\
\hline & & Preoperative & Postoperative & & \\
\hline 1 & 58 & 31 & 88 & 105 & No \\
\hline 2 & 54 & 40 & 97 & 115 & No \\
\hline 3 & 45 & 43 & 96 & 120 & No \\
\hline 4 & 43 & 28 & 92 & 115 & No \\
\hline 5 & 44 & 41 & 88 & 100 & No \\
\hline 6 & 42 & 44 & 86 & 105 & No \\
\hline 7 & 40 & 40 & 88 & 110 & No \\
\hline 8 & 25 & 36 & 92 & 120 & No \\
\hline 9 & 29 & 46 & 96 & 115 & No \\
\hline 10 & 33 & 38 & 90 & 105 & No \\
\hline 11 & 35 & 30 & 56 & 70 & Yes \\
\hline 12 & 42 & 35 & 86 & 105 & No \\
\hline
\end{tabular}


patients. Polymerase chain reaction for the mpt64 gene [3] was positive in all seven patients tested. Laboratory parameters of ESR and CRP returned to normal in eight patients by the fifth month and in the sixth to seventh months of ATT in four patients. None of our patients experienced changes in liver function, drug intolerance, or hypersensitivity reactions. At followup, none of the patients had progressive radiolucent lines or cavities around the prosthesis. It took 18 to 24 months for the bone density to appear similar on both sides.

\section{Discussion}

THA in patients with active TB is controversial $[10,12,13$, 15-17, 23]. However studies showing favorable microbiologic properties of MTB after ATT, and clinical success after implant use in patients with spinal TB with hip arthritis, prompted us to perform THA in patients with active TB and study their reactivation, laboratory findings, and clinical results $[7,9,15,16,25]$.

The study limitations were that this is a small series with short-term followup and the retrospective design means diagnostic criteria, surgical approaches, and medical management were not standardized. All patients in this study were diagnosed on the basis of clinical, biochemical, and radiographic findings, which are quite accurate in places endemic for $\mathrm{TB}$, and the microbiologic diagnosis was established after study of the tissue obtained at surgery $[2,23]$. However in the emergence of drug-resistant TB, we now routinely perform preoperative CT-guided biopsy, with specimens undergoing culture and sensitivity testing.

THA in a patient with quiescent TB of the hip is an established procedure [10, 12, 13, 15-17, 23]. However there is lack of consensus regarding the definition of a hip with quiescent TB. Some authors consider TB to be quiescent after 10 years of successful treatment [13, 15], others 20 years after a sinus stops draining or 10 years after an ankylosed hip [10], and others indicate the length of time of the inactive infection should not be a decisive factor and there always might be the risk of TB reactivation [12]. In two small case series reporting THA in patients with active $\mathrm{TB}$, the patients had no recurrences, and the authors emphasized adequate surgical débridement and ATT for a successful outcome (Table 4) [15, 25]. Several authors recommend preoperative chemotherapy from 1 to 4 weeks to as much as 3 months before any surgery in the presence of active infection [15, 23], and we empirically treated all patients a minimum of 4 weeks before surgery. This period allows stabilization of the lesion, improvement in soft tissue contractures with traction, and better planning of the reconstructive procedure. Postoperative chemotherapy is essential to control residual foci of TB [15, 23, 25]. Although the first-line drugs for ATT have been standardized, there still is no consensus regarding the duration. WHO guidelines recommend 6 months for extrapulmonary TB [24], whereas The Centers for Disease Control recommend 6 to 9 months for osteoarticular TB [1]. We followed the protocol at our institute for skeletal TB. If the patient's general condition shows marked improvement and the ESR and CRP return to normal by the fifth month, then we continue ATT until 1 year; however, if the ESR and CRP take more than 5 months to return to normal, we continue ATT until 18 months.

The presence of cemented or cementless implants seemingly has no influence on reactivation $[15,25]$. Our preference was uncemented prostheses for the femoral and acetabular sides, but in two patients older than 60 years, we preferred a cemented femoral component because we were not satisfied with the stability of the femoral uncemented prosthesis. In studies of THA in patients with quiescent TB $[11,17]$, reported reactivation rates were similar for cemented and cementless THAs, which indicates thermal reaction from cement is irrelevant to reactivation. In our study, one patient with cemented arthroplasty had reactivation owing to noncompliance with ATT. Insufficient research has been performed regarding the use of antituberculous drugs impregnated in cement, with studies on

Table 5. Comparison of ROM in active and quiescent TB

\begin{tabular}{lc}
\hline Study & $\begin{array}{l}\text { Average ROM } \\
\text { in flexion/extension plane }\end{array}$ \\
\hline Eskola et al. [6] & $86.1^{\circ}$ \\
Current study & $108^{\circ}$
\end{tabular}

$\mathrm{ROM}=$ range of motion.

Table 4. Review of case series

\begin{tabular}{llllllll}
\hline Study & Cases & Age (years) & Preoperative ATT & Type of THA & Followup (months) & HHS at followup & Reactivation \\
\hline Kim et al. [15] & 4 & 33.3 & Yes & C-THA & 33 & 86 & None \\
Yoon et al. [25] & 7 & 46.4 & No & UC-THA & 57.6 & 95 & None \\
Current study & 12 & 45 & Yes & 10-UC-THA & 41 & 88 & 1
\end{tabular}

C-THA = cemented THA; UC-THA = uncemented THA; ATT = Antitubercular therapy; HHS = Harris hip score. 
streptomycin, kanamycin, vancomycin, and rifampicin [14, $15,17,20]$. Nevertheless, recommendations regarding their use cannot be made based on these few reports. Isoniazid, rifampicin, and ethambutol are heat-stable, but the risk of toxicity and poor elution preclude their use until further research is performed [19].

In one of our patients with a large acetabulum (Fig. 2), we performed morselized allograft bone grafting after thorough curettage and débridement. At 46 months followup, the graft is well incorporated and the patient has no reactivation. Small cavitary defects, as reported in another study [25], also were left unfilled in our patients, and at followup these showed healing with new bone formation. Use of fresh-frozen allografts in patients with TB of the spine has shown incorporation and remodeling with no cases of collapse or reinfection [7].

Studies have reported that THA in the quiescent hip relieves pain and improves walking ability but improvement in range of movement was modest (Table 5) [6, 15, 17]. Yoon et al. [25] reported an improvement in HHS in their patients from 37 preoperatively to 95 at their last followup. In our patients, the HHS improved from an average of 38 to 88 . The slightly lower average score of our patients compared with the average score reported by Yoon et al. [25] was the result of one patient with a poor result who was noncompliant with ATT and followup protocol, resulting in persistence and reactivation of $\mathrm{TB}$ and sinus formation. She also had a pyogenic superinfection with Staphylococcus aureus and underwent implant removal and resection arthroplasty.

In the majority of patients with $\mathrm{TB}$ of the hip, the treatment comprising drug therapy, traction, and supervised mobilization produces good results, especially during the early stages of the disease. In patients who do not respond favorably to nonoperative treatment, joint clearance surgery (a combination of synovectomy and joint débridement) should be performed before the hip is destroyed and the hip should be immobilized in a functional position in a spica cast for 6 to 8 weeks followed by rehabilitation [2]. If unacceptable functional results are seen after adequate treatment, then depending on the amount of destruction and extent of fibrous ankylosis, we offer resection arthroplasty or THA to our patients. THA in active disease with advanced destruction is offered to a small proportion of patients who fulfill strict inclusion criteria.

Our experience with these patients allows us to believe THA is a safe procedure in active TB providing symptomatic relief, functional improvement, and early return to activity. We recommend preoperative culture and sensitivity and, in the absence of drug resistance to first-line drugs, to proceed with a single-stage procedure accompanied by thorough débridement to decrease the disease load in patients with advanced disease, followed by a complete course of ATT. Patient counseling regarding compliance with the ATT regimen and postoperative protocol is very important in ensuring success.

\section{References}

1. American Thoracic Society, Centers for Disease Control, Prevention/Infectious Diseases Society of America. Treatment of tuberculosis. MMWR Recommendations and Reports June 20, 2003/52(RR11);1-77. Available at: http://www.cdc.gov/mmwr/ preview/mmwrhtml/rr5211a1.htm. Accessed April 29, 2009. (Originally published as Blumberg HM, Burman WJ, Chaisson RE, Daley CL, Etkind SC, Friedman LN, Fujiwara P, Grzemska M, Hopewell PC, Iseman MD, Jasmer RM, Koppaka V, Menzies RI, O'Brien RJ, Reves RR, Reichman LB, Simone PM, Starke JR, Vernon AA; American Thoracic Society, Centers for Disease Control and Prevention and the Infectious Diseases Society. American Thoracic Society/Centers for Disease Control and Prevention/Infectious Diseases Society of America: treatment of tuberculosis. Am J Respir Crit Care Med. 2003;167:603-662.).

2. Babhulkar S, Pande S. Tuberculosis of the hip. Clin Orthop Relat Res. 2002;398:93-99.

3. Bhanu NV, Singh UB, Chakraborty M, Suresh N, Arora J, Rana T, Takkar D, Seth P. Improved diagnostic value of PCR in the diagnosis of female genital tuberculosis leading to infertility. J Med Microbiol. 2005;54(pt. 10):927-931.

4. DeLee JG, Charnley J. Radiological demarcation of cemented sockets in total hip replacement. Clin Orthop Relat Res. 1976; 121:20-32.

5. Engh CA, Bobyn JD. The influence of stem size and extent of porous coating on femoral bone resorption after primary cementless hip arthropasty. Clin Orthop Relat Res. 1988;231:7-28.

6. Eskola A, Santavirta S, Konttinen YT, Tallroth K, Hoikka V, Lindholm ST. Cementless total replacement for old tuberculosis of the hip. J Bone Joint Surg Br. 1988;70:603-606.

7. Govender S. The outcome of allografts and anterior instrumentation in spinal tuberculosis. Clin Orthop Relat Res. 2002;398:60-66.

8. Gruen TA, McNeice GM, Amstutz HC. "Modes of failure" of cemented stem-type femoral components: a radiographic analysis of loosening. Clin Orthop Relat Res. 1979;141:17-27.

9. Ha KY, Chung YG, Ryoo SJ. Adherence and biofilm formation of Staphylococcus epidermidis and Mycobacterium tuberculosis on various spinal implants. Spine. 2005;30:38-43.

10. Hardinge K, Cleary J, Charnley J. Low-friction arthroplasty for healed septic and tuberculous arthritis. J Bone Joint Surg Br. 1979;61:144-147.

11. Harris WH. Traumatic arthritis of the hip after dislocation and acetabular fractures: treatment by mold arthroplasty. An endresult study using a new method of result evaluation. J Bone Joint Surg Am. 1969;51:737-755.

12. Johnson R, Barnes KL, Owen R. Reactivation of tuberculosis after total hip replacement. J Bone Joint Surg Br. 1979;61:148-150.

13. Jupiter JB, Karchmer AW, Lowell JD, Harris WH. Total hip arthroplasty in the treatment of adult hips with current or quiescent sepsis. J Bone Joint Surg Am. 1981;63:194-200.

14. Khater FJ, Samnani IQ, Mehta JB, Moorman JP, Myers JW. Prosthetic joint infection by Mycobacterium tuberculosis: an unusual case report with literature review. South Med J. 2007;100:66-69.

15. Kim YH, Han DY, Park BM. Total hip arthroplasty for tuberculous coxarthrosis. J Bone Joint Surg Am. 1987;69:718-727. 
16. Kim YY, Ahn BH, Bae DK, Ko CU, Lee JD, Kwak BM, Yoon YS. Arthroplasty using the Charnley prosthesis in old tuberculosis of the hip: clinical experience with 8-10-year follow-up evaluation. Clin Orthop Relat Res. 1986;211:116121.

17. Kim YY, Ko CU, Ahn JY, Yoon YS, Kwak BM. Charnley lowfriction arthroplasty in tuberculosis of the hip: an 8- to 13-year follow-up. J Bone Joint Surg Br. 1988;70:756-760.

18. Mariconda M, Cozzolino A, Attingenti P, Cozzolino F, Milano C. Osteoarticular tuberculosis in a developed country. J Infect. 2007;54:375-380.

19. Marmor M, Parnes N, Dekel S. Tuberculosis infection complicating total knee arthroplasty: report of 3 cases and review of the literature. J Arthroplasty. 2004;19:397-400.

20. Masri BA, Duncan CP, Jewesson P, Ngui-Yen J, Smith J. Streptomycin-loaded bone cement in the treatment of tuberculosis osteomyelitis: an adjunct to conventional therapy. Can J Surg. 1995;38:64-68.

21. Oga M, Arizono T, Takasita M, Sugioka Y. Evaluation of the risk of instrumentation as a foreign body in spinal tuberculosis: clinical and biologic study. Spine. 1993;18:1890-1894.

22. Stewart PS, Costerton JW. Antibiotic resistance of bacteria in biofilms. Lancet. 2001; 358:135-138.

23. Tuli SM (ed). Tuberculosis of the Skeletal System (Bones, Joints, Spine and Bursal Sheaths). Ed 2. New Delhi, India: Jaypee Brothers Medical Publishers; 1997.

24. World Health Organization. Tuberculosis: global tuberculosis control report 2009. Available at: http://www.who.int/media centre/factsheets/fs104/en/index.html, Accessed May 6, 2009.

25. Yoon TR, Rowe SM, Santosa SB, Jung ST, Seon JK. Immediate cementless total hip arthroplasty for the treatment of active tuberculosis. J Arthroplasty. 2005;20:923-926. 